\title{
Pengaruh Terapi Konseling Realitas dalam Mengurangi Stigma Diri pada Penderita TB
}

\section{The Influence of Reality Counseling Therapy in Reducing Self-Stigma of Tuberculosis Patient}

\author{
Nur Maya Sari ${ }^{1}$, Khoidar Amirus ${ }^{2}$, Christin Angelina Febriani ${ }^{2}$ \\ ${ }^{1}$ Puskesmas Rawat Inap Satelit, Bandar Lampung, Indonesia \\ ${ }^{2}$ Fakultas Kesehatan Masyarakat Universitas Malahayati, Lampung, Indonesia
}

Korespondensi Author : fitria.wulandari@dsn.dinus.ac.id

Penyerahan: 23-11-2020, Perbaikan : 03-12-2020, Diterima: 23-01-2021

\begin{abstract}
Bandar Lampung was in second highest rank of tuberculosis cases. The objective of this research was to find out the influence of reality counseling therapy in reducing self-stigma of tuberculosis patient in Satelit Kota public health center working area in Bandar Lampung in 2020. This was a quantitative research by using quasi-experiment approach with two group pretest posttest design. Population was 106 TB patients in Satelit Kota public health center in Bandar Lampung. 26 respondent samples were taken by using purposive sampling and divided into two groups; reality counseling group and control group. Data were collected by using questionnaires. Data were analyzed with univariate analysis and bivariate analysis with $\mathrm{t}$-dependent test. The result showed that there were differences of stigma in control and experiment groups before and after reality counseling ( $p$-value $<0.001)$. The reality counseling had influence to reduce self-stigma of TB patient. The research recommends researcher on the same topic to compare with other therapy methods such as cognitive and group activity therapies.
\end{abstract}

\section{Keywords : reality counseling therapy, tuberculosis, self-stigma.}

\begin{abstract}
ABSTRAK
Bandar Lampung menempati urutan kedua tertinggi penemuan kasus TB. Promosi kesehatan berbentuk konseling realitas memiliki pengaruh dalam mengurangi stigma diri pada pasien TB untuk peningkatan kesehatan. Tujuan dari penelitian ini diketahui Pengaruh Terapi Konseling Realitas Dalam Mengurangi Stigma Diri pada Penderita TB di Wilayah Kerja Puskesmas Satelit Bandar Lampung. Penelitian kuantitatif dengan pendekatan quasy experiment dengan two group pretest-posttest design. Sampel penelitian ini adalah Pasien TB di Wilayah Kerja Puskesmas Satelit Bandar lampung sebesar 26 orang. Teknik pengambilan sample menggunakan purposive sampling. Sample dibagi menjadi dua kelompok yaitu kelompok yang diberikan konseling realitas dan kelompok kontrol. Analisis yang digunakan yaitu analisis univariat dan bivariat dengan uji T-Dependen (Paired-Samples T-Test dan uji T-Independen (Samples T-Test). Ada perbedaan stigma pada kelompok kontrol dan eksperimen sebelum dan sesudah diberikan konseling realitas dengan nilai $p$-value $<0.001$. Konseling realitas memiliki pengaruh dalam mengurangi stigma pada pasien TB. Saran untuk penelitian selanjutnya agar membandingkan dengan metode terapi konseling kognitif dan aktifitas kelompok.
\end{abstract}

Kata Kunci : Terapi Konseling Realitas, Tuberculosis, Stigma Diri 


\section{PENDAHULUAN}

Penyakit Tuberkulosis (TB) masih menjadi masalah kesehatan utama di dunia. Hal tersebut menyebabkan gangguan kesehatan jutaan orang pertahun dan menduduki peringkat kedua sebagai penyebab utama kematian akibat penyakit menular di dunia setelah HIV. Epidemi TB lebih besar dari perkiraan sebelumnya, mencerminkan data surveilans dan survei baru dari India. Namun, jumlah kematian akibat TB dan tingkat kejadian TB terus turun secara global dan di India. Pada 2015, diperkirakan ada 10,4 juta kasus TB baru (insiden) di seluruh dunia, di mana 5,9 juta (56\%) pada pria, 3,5 juta (34\%) pada wanita dan 1,0 juta (10\%) pada anak-anak. (WHO, 2016)

Berdasarkan Global Report Tuberculosis tahun 2017, secara global kasus baru tuberkulosis sebesar 6,3 juta, setara dengan $61 \%$ dari insiden tuberkulosis (10,4 juta). Tuberkulosis tetap menjadi 10 penyebab kematian tertinggi di dunia dan kematian tuberkulosis secara global diperkirakan 1,3 juta pasien. Angka insiden tuberculosis Indonesia 391 per 100.000 penduduk dan angka kematian 42 per 100.000 penduduk. (Kementerian Kesehatan RI, 2018). Tuberkulosis tetap menjadi masalah kesehatan global utama. Hal ini menyebabkan kesehatan memburuk sekitar 10 juta orang setiap tahun dan merupakan salah satu dari sepuluh penyebab kematian di seluruh dunia yang membunuh tiga orang dalam satu menit (Shiferaw \& Zegeye, 2019). Sekitar 75\% pasien TB adalah kelompok usia yang paling produktif secara ekonomis (1550 tahun). Diperkirakan seorang pasien TB dewasa, akan kehilangan rata-rata waktu kerjanya 3 sampai 4 bulan. Hal tersebut berakibat pada kehilangan pendapatan tahunan rumah tangganya sekitar 20-30\%. Jika ia meninggal akibat TB, maka akan kehilangan pendapatannya sekitar 15 tahun. Selain merugikan secara ekonomis, TB juga memberikan dampak buruk lainnya secara sosial stigma bahkan dikucilkan oleh masyarakat. (Lampiran Keputusan Menteri Kesehatan Nomor: 364/Menkes/SK/V/2009) Berdasarkan Buku Saku Kesehatan Provinsi Lampung, angka penemuan kasus TB (CDR) di Provinsi Lampung tahun 2002-2014 sebesar $17,6 \%-43,4 \%$. Angka penemuan kasus TB (CDR) semua kasus TB di Provinsi Lampung tahun 2015-2018 sebesar 41,6\%-44,39\%. Dari data tersebut angka penemuan kasus TB (CDR) mengalami peningkatan. Sedangkan angka kesembuhan TB (Cure Rate/CR) di Provinsi Lampung tahun 2012-2018 mengalami penurunan dari $72 \%$ menjadi $51 \%$. Khususnya di Kota Bandar Lampung, bahwa angka penemuan kasus TB (CDR) Tahun 2018 sebesar 44,62\% dan kegagalan pengobatan sebanyak 352 kasus (2,6\%). Hal ini menunjukkan bahwa penemuan kasus TB (CDR) belum mencapai target. Sedangkan pada Tahun 2019, angka penemuan kasus TB (CDR) sebesar 54,01\% dan kegagalan pengobatan sebanyak 134 kasus (0,9\%). Dari 15 Kabupaten/Kota di Provinsi Lampung, Kota Bandar Lampung menduduki peringkat kedua penemuan kasus terbanyak. (Data Dinas Kesehatan Provinsi Lampung, 2018 \& 2019).

Salah satu faktor penyebab tidak tercapainya angka penemuan kasus (Case Detection Rate) dan kegagalan pengobatan ini yaitu adanya stigma yang mempengaruhi perilaku pencarian kesehatan dan 121

Jurnal Dunia Kesmas, Vol. 10 No.1, Januari 2021, hal. 120-129

ISSN 2301-6604 (Print), ISSN 2549-3485 (Online) 
perawatan tepat waktu. Stigma terkait TB adalah penentu sosial yang penting bagi kesehatan. Penelitian umumnya menyoroti bagaimana stigma dapat berdampak besar pada individu dan masyarakat. Stigma tentang TB adalah penyakit orang miskin, penyakit keturunan dan penyakit tidak dapat disembuhkan (Depkes 2012). Stigma yang mereka dapatkan sangat mempengaruhi psikososial karena penderita TB akan merasa sedih, mengucilkan diri, menganggap dirinya tidak berarti dan malu untuk bersosialisasi. Dari dampak tersebut apabila penderita tidak memiliki mekanisme koping yang baik, maka penderita dapat mengalami stres yang berkepanjangan. (Masithoh et al., 2017). Tuberculosis berbahaya tetapi bisa diobati. Penyakit yang justru lebih berbahaya adalah diskriminasi dan stigma yang jelas-jelas bisa membunuh dan tidak ada obatnya. (Republika, Jakarta 2019).

Berdasarkan penelitian terkait yang dilakukan oleh Endria \& Yona (2019) tentang depresi dan stigma TB dengan kualitas hidup pasien Tuberculosis Paru di Poli Paru RSUP Persahabatan menunjukkan bahwa terdapat korelasi signifikan dari hasil uji bivariat tersebut 0,000 dengan tingkat kemaknaan (a) 0,05 menunjukan bahwa $\mathrm{p}$ value $<\mathrm{a}$ sehingga terdapat korelasi yang signifikan (bermakna) antara dua variabel. Dapat disimpulkan bahwa stigma terhadap penyakit ini akan memengaruhi kualitas hidup pasien tuberkulosis paru. Hal ini terkait dengan hasil penelitian terdapat hubungan yang bermakna dengan arah berlawanan (negatif) antara stigma dan kualitas hidup pasien tuberkulosis paru yang menjalani pengobatan OAT, kualitas hidup akan meningkat jika stigma terhadap penyakit ini rendah dan sebaliknya.

Dari hasil penelitian tersebut menunjukan bahwa pentingnya membangun kualitas hidup pasien TB. Adapun cara yang dapat dilakukan dalam membangun kualitas hidup pasien TB adalah dengan cara melakukan terapi, salah satunya yaitu dengan terapi konseling. Berdasarkan penelitian terkait yang dilakukan oleh (Mulyana \& Nursasi, 2019). Hasilnya menemukan empat studi tentang efektivitas studi perilaku kognitif (konseling) dan satu studi membandingkan terapi perilaku kognitif/konseling dengan psychoedukasi (PE) ditemukan lebih bermanfaat daripada intervensi Cognitive Behavior Therapy (CBT). Artikel lain menunjukkan lebih dari setengah dari sampel (50\%) dari penelitian menunjukkan bahwa terapi perilaku kognitif/konseling dapat mengurangi stigma diri. Menggunakan terapi perilaku kognitif/konseling efektif untuk membantu pasien TB untuk mengubah keyakinan negatif dan membingkai ulang kepercayaan mereka tentang penyakit mereka dan efeknya dapat membantu mengurangi stigma diri (Mulyana \& Nursasi, 2019).

Terdapat beberapa jenis konseling yang dapat dilakukan guna menanggulangi stigma pada pasien TB antara lain yaitu konseling kelompok pendekatan psikoanalitik, konseling kelompok pendekatan adlerian, konseling kelompok pendekatan terpusat (client centered), konseling pendekatan gestalt, konseling kelompok pendekatan rasional emortif terapi dan konseling kelompok pendekatan realitas. (Corey, 2013) \& (Rasimin \& Hamdi, 2019). 
Menurut (Corey, 2013), dari enam jenis konseling tersebut, konseling kelompok pendekatan realitas yang banyak dipakai dan direkomendasikan. Terapi realitas adalah terapi jangka pendek yang berfokus pada saat sekarang, menekankan kekuatan pribadi dan pada dasarnya merupakan jalan agar para anggota kelompok bisa belajar tingkah laku dan lebih realistis. Menurut Glasser (Corey, 2013), basis terapi realitas adalah membantu para konseling dalam memenuhi kebutuhan dasar psikologisnya yang mencakup kebutuhan untuk dicintai dan mencintai serta kebutuhan untuk merasakan bahwa kita berguna baik bagi diri sendiri maupun bagi orang lain. (Rasimin \& Muhamad Hamdi, 2019).

Berdasarkan hasil pra survei mengenai stigma diri yang dilakukan pada 30 responden penderita TB di Puskesmas Satelit Kota Bandar Lampung, didapatkan hasil pra survey responden yang mengalami stigma keterasingan sebesar $77,5 \%$, mengalami pandangan negatif (stereotip) sebesar $82,0 \%$, mengalami diskriminasi sebesar $76,6 \%$, adanya penarikan sosial sebesar 70,8\% dan adanya perlawanan stigma diri sebesar $66,0 \%$.

\section{METODE}

Penelitian kuantitatif dengan pendekatan quasy experiment dengan two group pretest-posttest design. Sampel penelitian ini adalah Pasien TB di Wilayah Kerja Puskesmas Satelit Bandar lampung sebesar 26 orang. Teknik pengambilan sample menggunakan purposive sampling. Sample dibagi menjadi dua kelompok yaitu kelompok yang diberikan konseling realitas dan kelompok kontrol. Analisis yang digunakan yaitu analisis univariat dan bivariat dengan uji $\mathrm{T}$ Dependen (Paired-Samples T-Test) dan uji T-Independen (Samples TTest).

\section{HASIL}

Tabel. 1 Karakteristik berdasarkan umur

\begin{tabular}{llll}
\hline Variabel & Mean & $\begin{array}{l}\text { Standar } \\
\text { Deviasi }\end{array}$ & Min-Maks \\
\hline Umur Responden & 38,19 & 14,305 & $15-60$ \\
\hline
\end{tabular}

Tabel. 2 Karakteristik berdasarkan Pendidikan

\begin{tabular}{rcc}
\hline Pendidikan & Frekuensi & Presentase \% \\
\hline SMA & 20 & $76,9 \%$ \\
D-3 & 5 & $19,2 \%$ \\
S-1 & 1 & $3,8 \%$ \\
\hline
\end{tabular}

Tabel. 3 Karakteristik berdasarkan Pekerjaan

\begin{tabular}{lll}
\hline Pekerjaan & Frekuensi & Presentase \% \\
\hline IRT & 4 & $15,4 \%$ \\
Wiraswasta & 19 & $73,1 \%$ \\
Pelajar & 3 & $11,5 \%$ \\
\hline
\end{tabular}

Tabel 4. Rata-rata Nilai Stigma Pada Variabel Intervensi dan kontrol Sebelum dan Sesudah dilakukan Konseling Realitas

Jurnal Dunia Kesmas, Vol. 10 No.1, Januari 2021, hal. 120-129

ISSN 2301-6604 (Print), ISSN 2549-3485 (Online)

http://ejurnalmalahayati.ac.id/index.php/duniakesmas/index 


\begin{tabular}{cccccccc}
\hline Kelompok & Variabel & Min & Max & Mean & Median & Std. dev & N \\
\hline Pretest & Kontrol & 76 & 95 & 80,83 & 80,00 & 5,132 & 12 \\
& Intervensi & 74 & 94 & 81,64 & 81,50 & 5,078 & 14 \\
\multirow{2}{*}{ Posttest } & Kontrol & 51 & 70 & 63,08 & 63,50 & 5,282 & 12 \\
& Intervensi & 51 & 70 & 59,14 & 58,00 & 5,545 & 14 \\
\hline
\end{tabular}

Hasil uji memperlihatkan diketahui bahwa rata-rata nilai stigma pada variabel kontrol sebelum dilakukan konseling realitas sebesar 80,83 dengan nilai terendah 76 dan nilai tertinggi 95, rata-rata nilai stigma pada variabel intervensi sebelum dilakukan konseling realitas sebesar 81,64 dengan nilai terendah 74 dan nilai tertinggi 94. Sedangkan rata-rata nilai stigma pada variabel kontrol sesudah dilakukan konseling realitas sebesar 63,08 dengan nilai terendah 51 dan nilai tertinggi 70, rata-rata nilai stigma pada variabel intervensi sesudah dilakukan konseling realitas sebesar 59,14, dengan nilai terendah 51 dan nilai tertinggi 70 .

Tabel 5. Perbedaan Stigma TB Pada Kelompok Intervensi Sebelum dan Sesudah Dilakukan Konseling Realitas

\begin{tabular}{clccccr}
\hline Kelompok & Variabel & $\Delta$ Mean & $\mathbf{9 5 \%} \% \mathbf{C I}$ & SD & P-value & $\mathbf{N}$ \\
\hline Pr- test & Intervensi & 81,64 & $78,71-84,57$ & 5,078 & \multirow{2}{*}{0,001} & 14 \\
Post test & Intervensi & 59,14 & $55,94-62,34$ & 5,545 & & \\
\hline
\end{tabular}

Diketahui bahwa nilai rata-rata mean pada saat diberikan pre test pada kelompok intervensi sebesar 81,64 . Nilai rata-rata mean pada saat diberikan post test pada kelompok intervensi sebesar 59,14. Hasil uji $T$ -
Dependen (Paired-Samples T-Test) diperoleh nilai $p$-value sebesar 0,000 $(p<0,05)$ maka dapat disimpulkan bahwa terdapat pengaruh terapi konseling realitas terhadap stigma TB pada pasien TB.

Tabel 6. Perbedaan Stigma TB Pada Kelompok Kontrol Sebelum dan Sesudah Dilakukan Konseling Realitas

\begin{tabular}{ccccccc}
\hline Kelompok & Variabel & $\Delta$ Mean & $\mathbf{9 5 \% C I}$ & SD & P-value & $\mathbf{N}$ \\
\hline Pre-test & Kontrol & 80,83 & $77,57-84,09-$ & 5,132 & 0,000 & 12 \\
Post test & Kontrol & 63,08 & $59,73-66,44$ & 5,282 & & \\
\hline
\end{tabular}

Diketahui bahwa nilai rata-rata mean pada saat diberikan pre test pada kelompok kontrol sebesar

\section{PEMBAHASAN}

Hasil analisa uji T-Dependen (Paired-Samples T-Test) diperoleh nilai $p$-value sebesar $0,000(p<0,05)$ yang berarti terdapat pengaruh terapi konseling terhadap Stigma TB antara kelompok intervensi dan kontrol
80,83 . Nilai rata-rata mean pada saat diberikan post test pada kelompok kontrol sebesar 63,08.

Sebelum dan Sesudah Dilakukan Konseling Realitas di wilayah kerja Puskesmas Rawat Inap Satelit Bandar Lampung tahun 2020. Hal ini menunjukkan bahwa konseling realitas dapat membantu mengurangi stigma diri negatif pada pasien TB. 
Didapat persentase lima skala stigma pada kelompok intervensi Sebelum dan Sesudah dilakukan konseling realitas yakni skala stigma keterasingan sebesar $(74,7 \%)$ dan $(54,8 \%)$, stigma dukungan stereotype sebesar $(65,2 \%)$ dan $(49,1 \%)$, stigma diskriminasi sebesar $(71,7 \%)$ dan $(48,5 \%)$, stigma penarikan sosial sebesar $(71,4 \%)$ dan $(53,3 \%)$, dan stigma perlawanan sebesar $(68,6 \%)$ dan $(48,9 \%)$ (rekapan hasil terlampir). Hal ini menunjukkan adanya perbedaan rata-rata nilai skala stigma pada kelompok yang tidak diberikan intervensi dan yang diberikan intervensi, disimpulkan bahwa responden mengalami pengurangan stigma diri pada pasien TB.

Berdasarkan teori (Rasimin \& Hamdi, 2019) konseling adalah upaya memfasilitasi individu agar memperoleh pemahaman tentang penyesuaian dirinya terhadap lingkungan. Berbagi pengalaman, pengembang wawasan, sikap dan keterampilan, pencegahan munculnya masalah, atau pengembangan pribadi. Konseling kelompok merupakan salah satu bentuk konseling yang memanfaatkan kelompok untuk membantu, memberi umpan balik (feedback), dan pemahaman belajar. Konseling kelompok dalam prosesnya menggunakan prinsip-prinsip dinamika kelompok.

Sejalan dengan hasil penelitian (Rama Hidayat, 2019) dengan judul hubungan stigma dengan harga diri pada pasien TB Paru, menunjukkan terdapat hubungan stigma dengan harga diri pada pasien TB Paru dengan angka signifikan $(p=0,000)$ dan arah hubungan negatif serta kekuatan korelasi sedang ( $r=-$ 0,474). Diharapkan petugas puskesmas dapat memberikan konseling kepada pasien TB Paru serta memberikan penyuluhan kepada pasien TB paru dan masyarakat sehingga dapat menghilangkan stigma pada pada penyakit TB sehingga tidak terjadi penurunan harga diri pada pasien TB Paru.(Rama Hidayat, 2019).

Berdasarkan penelitian terkait yang dilakukan oleh (Mulyana \& Nursasi, 2019), hasilnya menemukan empat studi tentang efektivitas studi perilaku kognitif (konseling) dan satu studi membandingkan terapi perilaku kognitif/konseling dengan psychoedukasi (PE) ditemukan lebih bermanfaat daripada intervensi CBT. Di artikel lain menunjukkan lebih dari setengah dari sampel $(50 \%)$ dari penelitian menunjukkan bahwa terapi perilaku kognitif/konseling dapat mengurangi stigma diri. Menggunakan terapi perilaku kognitif/konseling efektif untuk membantu pasien TBC untuk mengubah keyakinan negatif dan membingkai ulang kepercayaan mereka tentang penyakit mereka dan efeknya dapat membantu mengurangi stigma diri (Mulyana \& Nursasi, 2019).

Hasil analisis menggunakan uji T-Dependen (Paired-Samples T-Test) pada tabel bivariat diperoleh nilai $\mathrm{p}$ value sebesar $0,000(p<0,05)$ yang berarti terdapat pengaruh terapi konseling terhadap Stigma TB antara kelompok intervensi dan kontrol Sebelum dan Sesudah Dilakukan Konseling Realitas di wilayah kerja Puskesmas Rawat Inap Satelit Bandar Lampung tahun 2020. Hal ini menunjukkan bahwa konseling realitas memiliki pengaruh dalam mengurangi stigma diri negatif pada pasien TB.

Didapatkan juga hasil persentase terhadap lima (5) skala stigma pada kelompok intervensi dan

Jurnal Dunia Kesmas, Vol. 10 No.1, Januari 2021, hal. 120-129

125

ISSN 2301-6604 (Print), ISSN 2549-3485 (Online)

http://ejurnalmalahayati.ac.id/index.php/duniakesmas/index 
kontrol yakni pada skala stigma keterasingan diperoleh persentase pada Kelompok Kontrol Sebelum dan Sesudah dilakukan konseling realitas sebesar $(74,7 \%)$ dan $(52,8 \%)$, stigma dukungan stereotype sebesar $(61,1 \%)$ dan $(52,4 \%)$, stigma diskriminasi sebesar $(72,2 \%)$ dan $(56,3 \%)$, stigma penarikan sosial sebesar $(71,9 \%)$ dan $(56,6 \%)$, stigma perlawanan sebesar $(66,3 \%)$ dan $(53,8 \%)$ (rekapan terlampir). Hal ini menunjukkan adanya perbedaan rata-rata nilai skala stigma pada kelompok yang tidak diberikan intervensi dan yang diberikan intervensi, disimpulkan bahwa responden mengalami pengurangan stigma diri pada pasien TB

Berdasarkan teori (Rasimin \& Hamdi, 2019) konseling adalah upaya memfasilitasi individu agar memperoleh pemahaman tentang penyesuaian dirinya terhadap lingkungan. Berbagi pengalaman, pengembang wawasan, sikap dan keterampilan, pencegahan munculnya masalah, atau pengembangan pribadi. Konseling kelompok merupakan salah satu bentuk konseling yang memanfaatkan kelompok untuk membantu, memberi umpan balik (feedback), dan pemahaman belajar. Konseling kelompok dalam prosesnya menggunakan prinsip-prinsip dinamika kelompok.

Menurut (Corey, 2013) konseling kelompok meskipun masih ada tempat di lembaga masyarakat untuk konseling individu, yang memungkinkan adanya pembatasan dalam pemberian layanan ternyata model ini tidak lagi praktis dan efisien untuk masa sekarang. Konseling realitas sangat sesuai dengan permasalahan pada pasien TB yakni terkait stigma diri, dikarenakan terapi konseling realitas adalah suatu sistem yang difokuskan pada tingkah laku sekarang. Terapi berfungsi sebagai guru dan model serta mengonfrotasikan klien dengan caracara yang bisa membantu klien menghadapi kenyataan dan memenuhi kebutuhan-kebutuhan dasar tanpa merugikan dirinya sendiri ataupun orang lain. Terapi realita adalah penerimaan tanggung jawab pribadi yang dipersamakan dengan kesehatan mental. Terapi realitas adalah suatu sistem yang difokuskan kepada tingkah laku sekarang. Merupakan terapi jangka pendek yang berfokus pada saat sekarang, menekankan kekuatan pribadi, dan pada dasarnya merupakan jalan agar para anggota kelompok bisa belajar tingkah laku dan lebih realistik (Rasimin \& Hamdi, 2019).

Menurut (Corey, 2013), dari enam jenis konseling tersebut, konseling kelompok pendekatan realitas yang banyak dipakai dan direkomendasikan terutama di kalangan sekolah. Terapi realitas adalah terapi jangka pendek yang berfokus pada saat sekarang, menekankan kekuatan pribadi dan pada dasarnya merupakan jalan agar para anggota kelompok bisa belajar tingkah laku dan lebih realistis. Menurut Glasser (Corey, 2013), basis terapi realitas adalah membantu para konseli dalam memenuhi kebutuhan dasar psikologisnya yang mencakup kebutuhan untuk dicintai dan mencintai serta kebutuhan untuk merasakan bahwa kita berguna baik bagi diri sendiri maupun bagi orang lain. (Rasimin \& Muhamad Hamdi, 2019).

Berdasarkan hasil penelitian (Mariah \& Jamna, 2016) dengan judul efektifitas pelaksanaan bimbingan kelompok dengan pendekatan konseling realitas dalam mengembangkan penyesuaian diri 126

Jurnal Dunia Kesmas, Vol. 10 No.1, Januari 2021, hal. 120-129

ISSN 2301-6604 (Print), ISSN 2549-3485 (Online) 
siswa di lingkungan sekolah pada siswa kelas $X$ SMAN 1 Sungai Tarab menggambarkan bahwa terdapat perbedaan yang signifikan antara kondisi penyesuaian diri siswa di lingkungan sekolah sebelum dan setelah diberikan perlakuan berupa layanan bimbingan kelompok dengan pendekatan konseling realitas. Hasil pre test memperlihatkan bahwa ratarata siswa sulit menyesuaikan diri di lingkungan sekolah. Hal ini terlihat dengan rata-rata skor pre test sebesar 138.25 yang berada pada kategori kurang baik sebelum diberikan perlakuan. Setelah diberikan perlakuan terlihat perubahan pada diri siswa yang akhirnya sudah mulai mampu menyesuaikan diri di lingkungan sekolah. Hal ini terlihat dengan ratarata skor post test sebesar 166.83 yang berada pada kategori baik.

Penelitian ini sejalan dengan (Masithoh et al., 2017) terapi adalah suatu interaksi sistematis antara pasien dan terapis yang menggunakan prinsip-prinsip psikologi untuk mengatasi tingkah laku abnormal dan memecahkan masalah-masalah dalam hidup dan berkembang sebagai seorang individu. Ada beberapa terapi yang dapat digunakan untuk menaikkan harga diri, diantaranya terapi kognitif, grafoterapi, terapi aktifitas kelompok, penerapan konseling realitas, logoterapi dan psikoedukasi. Menurut pendapat peneliti, nilai rata-rata mean pada saat diberikan pre test pada kelompok kontrol sebesar 80,83 dan 80,00, sedangkan pada saat diberikan pre test pada kelompok intervensi sebesar 81,64 dan 81,50 . Nilai ratarata mean dan median pada saat diberikan post test pada kelompok kontrol sebesar 63,08 dan 63,50 sedangkan pada saat diberikan post test pada kelompok intervensi sebesar 59,14 dan 58,00. Hasil uji TDependen (Paired-Samples T-Test) diperoleh nilai $p$-value sebesar 0,000 ( $p<0,05)$ maka dapat disimpulkan bahwa terdapat pengaruh terapi konseling realitas terhadap stigma TB sebelum dan sesudah dilakukan konseling realitas, dikarenakan pasien TB mudah memahami dalam menerima materi konseling realitas yang disampaikan dan waktu pemberian konseling cukup efektif yakni konseling diberikan pada responden kelompok intervensi dengan individu dengan waktu 90 menit pada tiga (3) tahapan yaitu tahap awal, pertengahan, dan tahap akhir. serta jumlah kelompok yang ideal juga mempengaruhi. Sehingga responden dapat mengondisikan perasaan dan manajemen beban hidup yang dirasakan.

\section{KESIMPULAN}

Diketahui ada pengaruh terapi konseling realitas terhadap Stigma TB pada kelompok intervensi dan kontrol sebelum dan sesudah dilakukan Konseling Realitas di wilayah kerja Puskesmas Satelit tahun 2020, dengan nilai p-value sebesar 0,000 ( $p<0,05)$.

\section{SARAN}

Disarankan agar petugas promosi kesehatan Agar dapat memberikan pelayanan konseling realitas pada saat kunjungan rutin pasien TB, untuk memberikan motivasi serta dukungan pada pasien TB yang mengalami masalah dengan stigma diri agar dapat mengurangi stigma pada pasien $T B$, sehingga tidak menghambat proses pengobatan pasien TB. Bagi pasien TB agar dapat menerapkan sikap positif dan mekanisme koping yang telah diberikan selama konseling terhadap

Jurnal Dunia Kesmas, Vol. 10 No.1, Januari 2021, hal. 120-129 
keluarga dan masyarakat sekitar, sehingga tidak merasa dikucilkan dan rendah harga diri serta mengalami stigma negatif pada diri dan lingkungan. Dan bagi penelitian selanjutnya diharapkan agar melakukan penelitian antara metode konseling individu dan kelompok dengan berbagai sumber dan referensi yang kompeten agar dapat mengetahui keefektifan metode konseling.

\section{DAFTAR PUSTAKA}

Associations International Federation of Anti-Leprosy (ILEP) 1. (2011). ILEP Guidelines to reduce stigma: What is health--related stigma? 1. (June 2015). https://doi.org/10.13140/RG.2.1. 4553.3845

Corey, G. (2013). Teori dan Praktek Konseling \& Psikoterapi.

Craig, G. M., Daftary, A., Engel, N., O'Driscoll, S., \& Ioannaki, A. (2017). Tuberculosis stigma as a social determinant of health: a systematic mapping review of research in low incidence countries. International Journal of Infectious Diseases, 56, 90-100. https://doi.org/10.1016/j.ijid.201 6.10 .011

Franziska, L. (2013). Stigmatization, Discrimination and Illness.

Hastono, S. P. (2016). Analisis Data Pada Bidang Kesehatan (p. 250 halaman). p. 250 halaman.

Hidayati, E. (2015). Pengetahuan Dan Stigma Masyarakat Terhadap TBC Setelah Diberikan Pendidikan Kesehatan Pencegahan Dan Penularan. Soedirman Journal of Nursing, 10(2), 76-82.

Husnaniyah, D., Lukman, M., \& Susanti, R. D. (2017). FaktorFaktor Yang Berpengaruh Terhadap Harga Diri (Self Esteem) Penderita Tuberkulosis Paru Di
Wilayah Eks Kawedanan Indramayu. The Indonesian Journal of Health Science, 9(1), 112.

International Federation of AntiLeprosy Associations (ILEP) 2. (2011). Guidelines to reduce stigma 2. PLoS Neglected Tropical Diseases, 11(1), 1-2. https://doi.org/10.1093/inthealth /ihw006

Kemenkes. (2016). Permenkes Nomor 67 Tahun 2016 tentang Penanggulangan Tuberkulosis.

Kementerian Kesehatan RI. (2018). Profil Kesehatan Republik Indonesia Tahun 2017.

Liamputtong, P. (2013). Stigma, Discrimination and Living with HIV/AIDS. In Stigma, Discrimination and Living with HIV/AIDS. https://doi.org/10.1007/978-94007-6324-1

Masithoh, A. R., Qasanah, I., Hertiana, D., Studi, P., Keperawatan, S., Tinggi, S., ... Kudus, M. (2017). Pengaruh Terapi Psikoedukasi Keluarga Terhadap Harga Diri Penderita TBC di Wilayah Kerja Puskesmas Undaan Kabupaten Kudus Tahun 2015. 1,2,3 Progam Studi S1 Keperawatan, Sekolah Tinggi IImu Kesehatan Muhammadiyah Kudos, 529-538. Retrieved from http://journal.ummgl.ac.id/index. php/urecol/article/download/1870 /1088/

Mitchell, E. M., van den Hof Authors Agnes Meershoek, S., Zwerling, A., Daftary, A., Citro, B., Smyth, C., ... Kipp, A. (2018). Proscovia Nanyanzi Luzige (National Forum of People Living with HIV/AIDS Networks in Uganda. Jefry Acaba (APCASO). Retrieved from www.challengetb.org 
Mulyana, R., \& Nursasi, A. Y. (2019). The Intervention Strategies To Reduce Tuberculosis Stigma Based On Community: A Systematic Review. Jurnal Pendidikan Keperawatan Indonesia, 5(1), 15-24. https://doi.org/10.17509/jpki.v5i 1.16371

Notoatmodjo, S. (2018). Metodologi Penelitian Kesehatan (p. $236 \mathrm{hlm}$ ). p. $236 \mathrm{hlm}$.

Puspasari, S. fina A. (2019). Asuhan Keperawatan Pada Pasien Dengan Gangguan Sistem Pernapasan ( $p$. 352 halaman). p. 352 halaman.

Rama Hidayat. (2019). HUBUNGAN STIGMA DENGAN HARGA DIRI PADA PASIEN TB PARU DI WILAYAH KERJA PUSKESMAS ANDALAS PADANG.
Rasimin \& Hamdi. (2019). Bimbingan dan Konseling Kelompok.

Shiferaw, M. B., \& Zegeye, A. M. (2019). Delay in tuberculosis diagnosis and treatment in Amhara state, Ethiopia. BMC Health Services Research, 19(1), 1-8.

https://doi.org/10.1186/s12913019-4056-7

WHO. (2006). Diagnostic and treatment delay in tuberculosis. Retrieved from http://applications.emro.who.int/ dsaf/dsa710.pdf.

WHO. (2016). World Health Organization. 44(1), 23-63. https://doi.org/10.1183/0903193 6.00188313

Willis, S. (2019). Konseling Individual Teori dan Praktek. 